established the Anthropological Institute of Great Britain and Ireland with Sir John Lubbock as its first president. With the financial help of the British Association, the revised "Notes and Queries in Anthropology" were published; the Anthropometric Committee of 1875 gave much needed definition to physical anthropology; and its annual measurements of the members of the British Association did much to popularize statistical treatment of its problems. Organized by Francis Galton, this was the precursor of the Galton Laboratory at University College, London, and of the systematic study of biometry and eugenics in Britain.

When the original library and museum, at $4 \mathrm{St}$. Martin's Place, W.C.2, were pulled down, the good offices of the president of 1883-85, William Henry Flower, secured an appropriate home in the upper part of the Zoological Society's house at 3 Hanover Square. This arrangement, however, was nearly disastrous to both institutions, for the weight of exhibits from the first excavation of Stonehenge (1901-2) irretrievably damaged the building and hastened the transfer of the Zoological Society's offices to Regent's Park. By this time the close association of the Institute with the ethnological staff of the British Museum, inaugurated by Augustus Franks and extended by Charles Hercules Read and others down to the present time, drew the Institute into a succession of abodes in Bloomsbury, the last of which, 21 Bedford Square, is within a few yards of the original meeting room in the house of Thomas Hodgkin.

Of the mature work of the Institute only outlines are possible here. Like its predecessors, it has never been rich, and has owed much to benefactions supplementary to its normal income; from the Carnegie Trustees for the improvement of its valuable library, from the Rockefeller and Laura Spelman Rockefeller Foundations to maintain its Journal, and from other friends for a few small expeditions. But it has never had the popular appeal of the Zoological or the Royal Geographical Society, or the support of academic or industrial interests. Side by side with its proper business of the promotion and publication of research, it has never ceased to urge on the Colonial Office and other public agencies the pressing need for expert acquaintance with the customs and mode of life of the native peoples of the British Empire; but until recently with disappointing response, in comparison with stately institutions such as the Colonial Institutes of the Netherlands and of Belgium, and the Bureau of Ethnology in Washington. Even the urgent task of recording institutions and modes of life which have been fading away before our eyes has been postponed irretrievably. The inevitable dissipation of energies in specialist societies has been minimized by the establishment of research committees within the Institute itself, for India, Africa, Anthropometric Standards, and the like, and of a Joint Committee for Anthropological Research and Teaching, on which universities and independent institutions are entitlod. to be represented, which has no parallel in other branches of learning in Great Britain. In the generation following the war years 1914-18, as the spokes. man of that Joint Committee, the Anthropological Institute has twice taken decisive part in the organization of the International Congresses for Prehistoric and Protohistoric Sciences (London 1932, Oslo 1936) and for Anthropological and Ethnological Sciences (London 1934, Copenhagen 1938), which have provided at least the constitutional foundations for worldwide co-operation on liberal lines in time to come.

\section{ACTIONS OF DRUGS}

$\triangle$ BOUT two hundred and fifty persons attended A a discussion in London on September 24 organized by the Faraday Society and entitled "Modes of Drug Action". The meeting lasted six hours and a wide ground was covered by the papers, which had been circulated in proof. These papers contained much interesting matter and it was perhaps unfortunate that too large a proportion of the available time and energy of the meeting was devoted to listening while they were expounded. In the following account the order in which the papers were given has been altered.

Prof. E. K. Rideal, who took the chair, paid a tribute to Sir William Hardy, who was responsible for initiating these joint discussions between biologists and physical chemists. Sir Henry Dale, in his general introduction, stressed the complexity of the problems of pharmacology and warned the meeting against the optimistic adoption of simple theories to explain complicated facts. Most of the generalizations that have been made have exceptions, and it is on these that attention should be focused.

Prof. J. H. Gaddum discussed the antagonism of drugs, and the quantitative relations between the antagonists. It is important to distinguish two kinds of interaction, both of which may give rise to graded antagonism over a wide range of concentrations. Some antidotes neutralize poisons by forming inert compounds with them, as SH- compounds do with mercury. In this case the study of the antidote throws no light on the action of the drug on the tissue. Its action is merely to reduce the concentration of free poison present.

Other antidotes act by competing with poisons for chemical groups essential to living tissues. The study of these is more interesting, since it allows drugs to be classified according to their antagonists, and may provide evidence about the particular chemical processes in the cell with which the drugs interfere. The work of Woods on the antagonism of sulphanilamide and para-aminobenzoic acid is a striking example of work in this field. The quantitative relationships between antagonists were discussed. If the reactions are of the first order, the ratio of the concentrations of the two drugs which together produce a given effect should be constant, provided that the concentrations of one drug are calculated as differences from the threshold concentration. This is true whether the drugs neutralize one another or compete, so that it is impossible to distinguish the two kinds of antagonism except from independent evidence that the drugs either combine with one another or have molecules which would be likely to combine with similar groups in the tissues.

Dr. H. R. Ing discussed the theory that drugs combine with specific receptors in tissues and the extent to which it can be used to interpret the relation between chemical constitution and pharmacological action. When a series of allied drugs is studied, it is often possible to recognize pharmacodynamic groups which appear to be essential for one particular type of action. It might be said that this group is essential for combination with the receptors, but there are anomalies. The same pharmacodynamic group is commonly present both in active drugs and in their antagonists. The results can be explained in terms of competition between the two drugs for the receptors, if it is assumed that one of them causes an active response and the other blocks the receptors 
but causes no response. Since drugs with a feeble action do not antagonize drugs with a greater action on the same receptors, the response must depend only on the amount of drug combined with the receptor and not on the magnitude of its effect when so combined, which must be all or none. The receptor theory provides a useful intellectual framework for the consideration of the qualitative aspects of the problems presented by the structure and action of drugs. We do not know enough of the receptors to predict the effects of minor changes in the molecule.

The relations between in vivo and in vitro actions of chemotherapeutic agents were discussed by Dr. H. Mollwain. He gave an able summary of the extensions of the theories of Fildes and Woods which have enabled him to discover new types of therapeutic agent by using substances similar in chemical structure to the normal metabolites of bacteria. The results obtained in the body are complicated by variations in the concentrations of antagonistic substances, and by the actions of the body on the drug and the drug on the body. These interactions are not always the same in different species of animal and under different conditions, and $a$ complete picture can only be attained by correlating observations on whole animals with those obtained in vitro.

Sir Rickard Christophers gave an account of work on the metabolism of the malaria parasite, which consumes oxygen at a high rate $\left(Q_{0}=35\right)$ and utilizes glucose if it is present, but can utilize various other foodstuffs in the absence of glucose. Drugs which are used in the treatment of malaria inhibit the oxygen consumption when they are present in concentrations such as may occur in the blood in treatment. This work provides an opportunity for studying the action of these drugs in vitro, and so measuring the activity of drugs, without having to consider the complicating effects of differences in their rates of absorption and excretion.

Dr. E. M. Lourie discussed the failure of some arsenical drugs to penetrate the blood-brain barrier and so to act on trypanosomes in the brain in the late stages of sleeping sickness. The best method of studying this problem is probably the estimation of the trypanocidal power of the cerebrospinal fluid when the drugs are administered; but even then, drugs may reach the fluid through the choroid plexus without ever coming in contact with the brain cells. There is some evidence that acid compounds penetrate the barrier more readily than basic or neutral compounds.

The relation between the chemical structure of organic arsenicals and their combination with trypanosomes was dealt with by Dr. H. King. He divided these drugs into three classes; some, like phenylarsenoxide, are active because their properties make them concentrate at lipoid interfaces; some, like atoxyl, show large differences in their actions on normal strains and drug-resistant strains of trypanosomes, and these probably combine with the organism in the same way as acridine dyes; others, like phenyl glycine arsenoxide, are probably not concentrated in the organisms at all. These factors control the combination between drug and organism. The subsequent action of the drug probably depends on quite other factors, such as a combination with SH- groups.

Dr.J. H. Quastel discussed the action of narcotics, and of amphetamine, on the central nervous system. Nareotics reversibly inhibit the oxygen iptake of minced brain, or of brain slices, in concentrations similar to those occurring during anæesthesia in the whole animal. The effect is most marked when the substrate is glucose, and is almost absent, when the substrate is succinate. They also specifically inhibit glycolysis in other tissues; but there is evidence that the brain is particularly dependent on glucose metabolism, and that may be why the brain is particularly susceptible to narcosis. Tyramine, and some other amines, cause a diminution of the respiration of brain, which increases with time and is due to an aldehyde formed from tyramine by amine oxidase. It is suggested that the wakening effect of amphetamine, and other amines which inhibit amine oxidase, is due to inhibition of the formation of aldehydes, which are normally present and which normally cause a partial depression of the central nervous system.

Prof. F. Weigert described experiments on the fate of benzpyrene in the body. The long latent period in the carcinogenic action of this substance raises the question whether it persists throughout this time as such, or is changed into some other carcinogenic substance. The substance itself and some of its products in the body can be detected by their fluorescence and purified by chromatography. One of these products is particularly liable to collect in the tissues where cancer is liable to occur, and may be the immediate cause of the cancer.

Prof. E. K. Rideal discussed the general question of the combination of drugs with tissues in terms of electron chemistry. The forees involved are complex and can profitably be studied by measuring the energy of adsorption of drugs on proteins, by the chromatographic method and by putting drugs in solution beneath monolayers in a trough. The application of these methods to pharmacological problems is still in an embryonic stage, but holds the promise of explaining the behaviour of drugs in terris of the detailed constitution of their molecules.

Dr. J. H. Schulman emphasized these views by giving actual examples. It has, for example, been shown that the lytic activity of a series of surfaceactive long-chain paraffin ionic salts bears relation only to their surface activity at a cholesterol or protein interface, and in no way to their effect on the surface tension at an air-water interface. The optimum activity of synthetic oestrogens is correlated with their adsorption at a protein interface. The adsorption of proteins causes precipitation of lipoid emulsions provided that the charge on the protein is the opposite of that on the emulsion. The effects of using emulsions with different charges, and different proteins at different hydrogen ion concontrations, can be successfully predicted from this theory.

Dr. H. Hurst spoke at some length of the actions of drugs on insects, and emphasized the fact that when the drug is applied to the outside of the insect its action is very much influenced by the permeability of the cuticle. His vicws on this subject have recently been published in NATURE $(152,292 ; 1943)$.

Three papers from the Physical Chemistry Laboratory at Oxford described studies of the growth of $B$. lactis aerogenes in artificial culture. There is normally a lag-phase followed by a phase of exponential growth, and the growth then slows up again and the population eventually becomes constant. Dr. R. M. Lodge and Prof. C. N. Hinshelwood described the adaptation of the organism when it is transferred from bouillon to a simpler synthetic medium. In the first fow subcultures growth is slow, and abnormally long, snake-like cells are formed. It 
is concluded that separate mechanisms, responsible for $(a)$ the removal of growth inhibitors, $(b)$ elongation and $(c)$ division, become adapted at different rates to the new medium.

Dr. G. H. Spray and Dr. R. M. Lodge described the effects of resoreinol and $m$-cresol, which cause a prolongation of the lag rather than a slowed rate of growth, or a diminution of the stationary population. Resorcinol is eventually completely inactivated by the bacteria, but $m$-cresol is not. Long, snake-like bacteria can be produced by $m$-cresol under certain conditions. Dr. D. S. Davies and Prof. C. N. Hinshelwood described the effects of sulphonamides, which both increase the lag and reduce the growth-rate, but do not inhibit growth completely even in high concentrations. On subculture in the presence of sulphonamides the organisms become immune to the drug. Thus immunity is at first partial, reversible and specific to the particular sulphonamide (sulphanilamide or sulphaguanidine) used. After thirty subcultures it becomes complete, irreversible and unspecific. The theory that this is due to the selection of resistant organisms is rejected, and it is assumed that the cells develop enzymes which produce a sulphonamide antagonist. The partial antagonism which develops earlier is probably due to other causes.

A full account of the meeting will appear in the Transactions of the Faraday Society.

\section{J. H. GADDUM.}

\section{AREA HEATING}

$\mathrm{T}$ HE publication of recent technical papers* on so-called district heating emphasizes a grave omission in the County of London Plan; indeed, the term is mentioned a few times, but there is no consideration of the very great contribution this development of applied science can make, on several grounds, to the social development of large population groups which have arisen in Great Britain, especially the conurbation of London. The subject is very briefly mentioned in the exhibition of planning now open at the Institution of Civil Engineers, held jointly by that body and the Institution of Municipal and County Engineers. Twice in the last twenty years St. Marylebone Borough Council, which generates its own power, discussed supplying the local housing estates with heat, but failed to grasp the opportunity of obtaining experience in this field.

There is a ray of hope, however; Coventry has just agreed to incorporate district heating in its reconstruction programme. The local authority still has to convince the Electricity Commissioners, and then bring a Bill before Parliament. Further, the Public Works Committee of Bristol has had submitted to it a plan to cover the central area of that city.

The major public difficulty is that the existence of district heating is not obvious. It is not like a railway, bridge, or power-transmission line, which anyone can observe or appreciate for use or value. District heating is not known in Great Britain, whereas it is a national policy in the U.S.S.R.; Russian schemes already dispose of more heat than is conveyed by all the town-gas in Britain. Hamburg has had it on an increasing scale for half a generation, and each of the latest German schemes is larger than the New York plant, which uses 775,000 tons of coal annually.

What, then, are the virtues of district heating ?

* Electrical Times, Sept. 30 and Oct. 14, 1943; Engineering, * Electrical Times, Sept. 30 and Oct, 14, 1943;
oct. 8,1943 ; Industrial Heating Engineer, July-0ct. 1940.
Practically all electric power in Great Britain is generated by high-pressure and high-temperature steam, dropping its entropy in turbo-generators. The maximum working efficiency of energy conversion from coal to electricity is not likely to exceed 30 per cent in the most modern, and consequently all new, power stations; it averages 20-25 per cent. The major loss is in the condensation of the steam at low-pressure, necessary for the operation of steam turbines; that is, the latent heat is wasted. In other words, every large power station is throwing away a million kilowatts continuously into the local river or its cooling towers.

The usage of electric energy is increasing at a rapid rate, and in many large places, which provide centres of gravity of electric loading, new power stations will be required. London after the War will, it is probable, require several new power stations or great extensions to cope with the increasing load. The more electric energy is used under the present system, the more coal energy is wasted. The natural and obvious proposal is to utilize this wastage of heat for domestic and process work in the neighbourhood of these power units.

Continental practice shows that a distribution of this waste heat is easily economical up to seven miles, and, in favourable circumstances, several times this. It is calculated that with reasonable capital expenditure, which can be amortized in between five and fifteen years, depending upon the particular circumstances, such heat can be sold at not more than $4 d$. per therm; this would make important contributions to coal conservation.

A more attractive scheme is to burn the coal in boiler stations, in which can be realized efficiencies of conversion up to 90 per cent, on the rim of large centres of population, transmit the steam through large pipes to turbo-generators located at the centre of gravity of the electric load, and dispose of the heat, which otherwise would be wasted, in the surrounding domestic and industrial areas. The wastage of heat in such pipe transmission is of the order of 1 per cent for seven miles, because of the very large diameter required; the pipe need not be lagged with heat-conserving material. In one step we save the expensive area required for a coal depot essential now to every power station, the consequent dirt which arises from coal and ash handling, and any more which is permitted by expensive smoke cleaning plant to escape through unsightly chimneys; we have saved not only the cost of expensive condensing plant, and cooling towers on non-river sites, but also, in the latter case, expensive ground and the enormous amount of condensation which is inevitable in their region during humid weather. The problem of noise arising from generators in a comparatively small building can easily be coped with by modern methods of noise control.

Having decided to dispose of hitherto wasted heat -and it may be remarked that it is not possible to extract much heat from existing power stations because the full benefits are not realizable without special designs of back-pressure turbines-the problem is to distribute such heat in the form of hot water or steam at high pressure to the situations where it can be utilized. Naturally, the regulation of demand, which would not be exactly in step with the electric power demand, causes some difficulty, but this can be overcome by having adjustable back-pressure on the turbines with suitable heat-reservoirs, these taking the form of lightly heat-insulated steel water- 